Journal of Conservation Science

Vol.35, No.1, pp091-098(2019)

DOI https://doi.org/10.12654/JCS.2019.35.1.10

pISSN: $1225-5459$

Printed in the Republic of Korea

\title{
An Analysis Study of Wall Painting Pigment Excavated at Iksan Jeseoksaji Dumpsite
}

\author{
Mi Jeong Kim | Ji Hyun Cho' | Dong Hyeok Moon* | Hong Ju Jin* \\ Buyeo Naitional Research Institute of Cultural Heritage, Buyeo, 33123, Korea \\ *Division of Conservation Science, Naitional Research Institute of Cultural Heritage, Daejeon, 34122, Korea \\ ${ }^{1}$ Corresponding Author: hkeeper627@korea.kr, +82-41-860-5675
}

\begin{abstract}
The fragments of a wall painting excavated from among the historical remains of Jeseoksa Temple in Iksan. The extent of the damage to the fragments was examined and an analysis of the components of the pigment was conducted. The results of the component analysis of the pigment confirmed that the white pigment consisted of alkali feldspar and mullite. Although the results of the visual inspection revealed differences in color in the red and black pigments, the main component of the two colors was confirmed to be iron oxide. Red and black pigments are found at the same position. Although differences of color is obvious, those are identified as hematite and magnetite of oxidized steel's affiliation. It is judged that Differences of ingredients happened by external environment's factors.
\end{abstract}

Key Words: Jeseoksaji, Wall painting Fragments, Pigment, Pigment of Baekjae

\section{INTRODUCTION}

The dumpsite of the original Jeseoksa Temple in Iksan is located in Wanggung-ri, Wanggung-myeon, Iksan-si, Jeollabuk-do, some 400 meters northeast of the central part of the Jeseoksa Temple site(Designated Historical Site \#405). According to a record in Gwanseeum eungheomgi (觀世音應驗記), the site was destroyed by a fire resulting from a lightning strike in A.D. 639, when China was ruled by Emperor Taizong of Tang(貞觀). At that time, the waste materials resulting from the fire and the subsequent collapse of the temple were disposed of at a place now known to be the historical remains of the Jeseoksa Temple site(Buyeo Research Institute of Cultural Heritage, 2011). In the period 2003-2004 a survey was carried out of the site's northeastern area, which was known as a roof tile kiln site in Wanggung-ri. During this survey and the subsequent excavation project, several historical relics including Roof-end tiles with Lotus Design, a clay statue that showed signs of having been burnt, a statue of a demon, and fragments of a wall dating from the first half of the seventh century were discovered, and these findings helped confirm that the site was in fact the dumpsite of the original Jeseoksa Temple.
It is expected that these historical remains will help determine the wall fragments of the original temple and its main period of activity. They can also be compared with the relics excavated from the sites of Yeongryongsa(永寧寺) Temple in Luoyang, China, Jeongnimsa Temple(定林寺址) Site in Buyeo(an ancient Korean kingdom), and Gawaharadera (川原寺) Temple in Japan in order to shed light on cultural exchanges between Korea, China and Japan, in which the kingdom of Baekje played an important role(Buyeo Research Institute of Cultural Heritage, 2013). As regards the vestiges of the wall recovered from among the excavated relics, a detailed examination of them was not easy as they were in very poor condition and kept breaking into pieces even during the survey. As the excavation of a wall painting is a rare event, there have been few studies of such wall paintings(Yang, 2014). Accordingly, as part of this research, an analysis was conducted of the components of the pigment wash and the coloring traces on the surface of the fragments of the wall painting excavated from the dumpsite of the Jeseoksa Temple, the results of which could be used as basic data in a study of the coloring pigments used during the Sabi era of the Baekje kingdom. 


\section{RESEARCH TARGET AND METHOD OF RESEARCH}

\subsection{Research target}

Only fragments of wall remained after destroying the structure, not the complete shape of wall. It is part of wall through main points of wood identified at the back of fragments. Excavated fragments are very small quantities, and 4 points are selected among the fragments of wall possible to collect the sample. The subjects of the research were coated with a surface layer of thin pigment wash of 0.5 1 $\mathrm{mm}$, while red and black layers of color were partially identified on top of the white layer. The size and form of the coloring layers were diverse. In addition, organic substances, etc. were found on the broken cross section of the fragments, which are assumed to have been added in order to increase cohesion when the wall was built. It is also assumed that the roots of plants added at the time of collapse and burial. Some of the excavated fragments exhibited burn marks. As regards the subject JS1, the overall background layer was white, with red and black coloring traces assumed to be the remains of actual images. In addition, the back of the colored surface showed traces of wooden members that are thought to have been used to support the wall. As regards the subject JS1, a red sample was collected as the red layer was in relatively better shape.

As for the subject JS2, it is smaller than the others, and is red color at the center with an overall background layer of white and dark brown, and a black layer along the edge. A sample was taken from its red and dark brown or black areas. As for JS3, it has an overall background layer of white, with red or black layers partially observed. As its white layer is thicker than that of the other two subjects, a sample was taken from it; and a sample was also collected from its red and black layers. As regards JS4, a sample was taken only from its white layer as it was brighter than that of the other subjects. All the samples were taken from areas where it was possible to do so, or from pieces that had broken away. Separate samples were taken for each color(i.e. white, red, black). Photographs of the wall fragments and the list of samples are as follows(Table 1, Figure 1).

\subsection{Method of research}

In order to check the condition of the wall painting images excavated from among the historical remains found at the dumpsite of the original Jeseoksa Temple, their surface was photographed using a multimedia video microscope(DG-3x, Scalar, Japan), and the differences in each color were measured using a portable color difference meter(CM-2600d, Minolta, Japan). For the color difference measurement standard, the CIE $\mathrm{L} \mathrm{a}^{*} \mathrm{~b}^{*}$ value specified by the International Commission on Illumination(CIE) was used. For the cross-section analysis of the colored layers of the wall painting fragments, and the chemical analysis of the pigments used, samples were taken from each layer of color of the wall painting fragments. The samples were polished after cold mounting, and the cross-section composition of the coloring layers was examined using an optical microscope. The main components of the polished samples were analyzed using an Energy Dispersive X-ray Spectrometer attached to a Scanning Electron Microscope after surface coating with $20 \mathrm{kV}$, probe current $60, \mathrm{Pt} / \mathrm{Pd}$. The main components of the colored layers are analyzed with wavelength dispersive X-ray spectrometer. Samples of
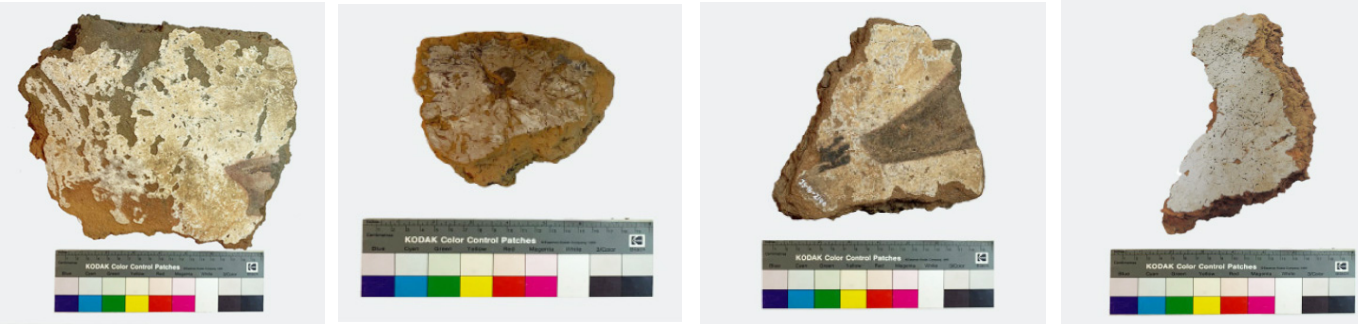

Figure 1. Photos of the wall structure fragments excavated at Iksan Jeseoksaji dumpsite. 
Table 1. Sample list of wall fragments in Jeseoksaji dumpsite of Iksan

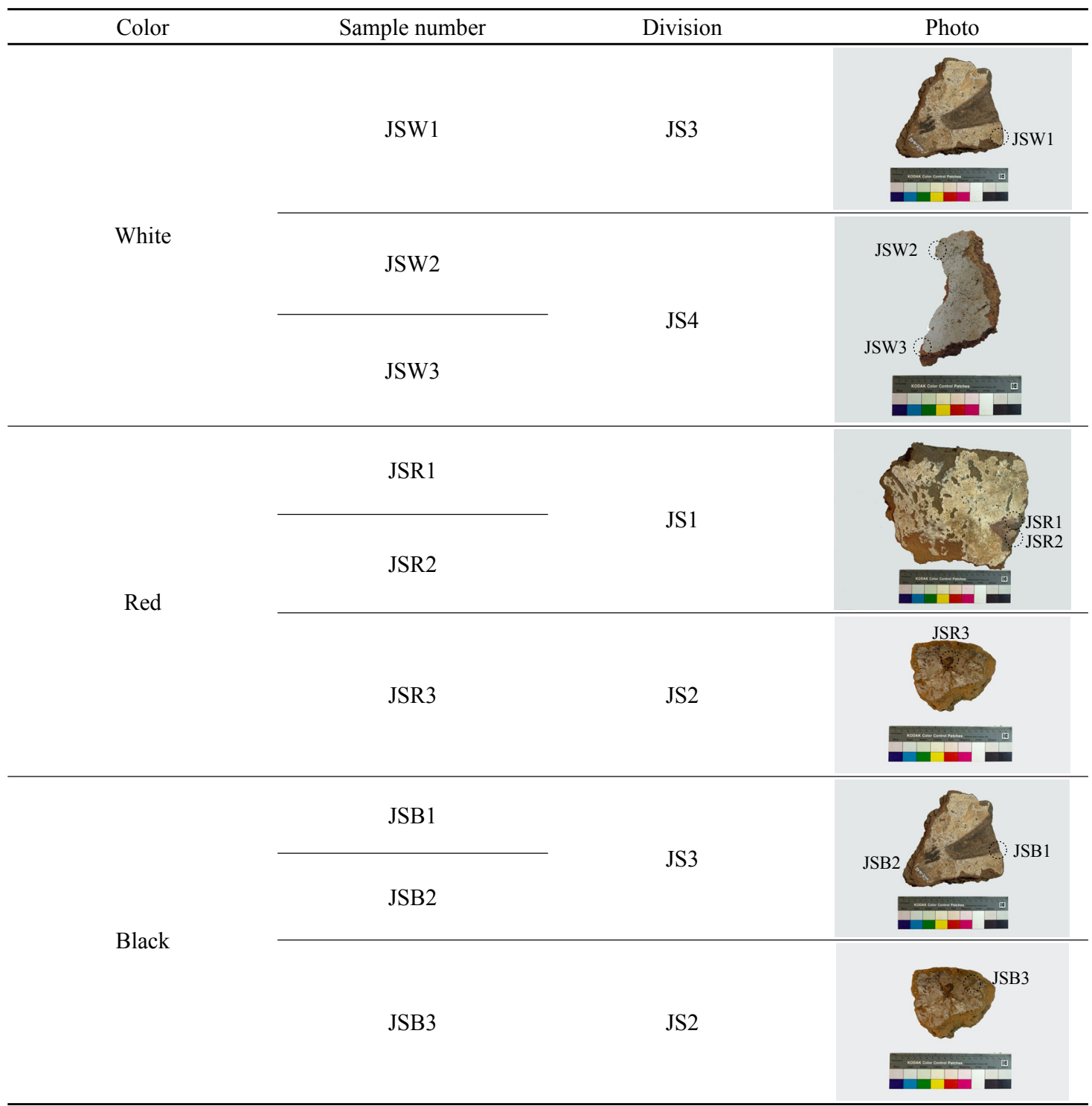

each color were sampled at available sampling locations and classified into colors by powdering. The analysis conditions were set to $40 \mathrm{kV}, 40 \mathrm{~mA}, 5^{\circ} \sim 60^{\circ}, 0.013^{\circ} / \mathrm{sec}$.

\section{RESULTS AND CONSIDERATIONS}

\subsection{Damage condition}

The wall painting, which was broken up and buried at the time of the fire that destroyed the original Jeseoksa temple, was excavated in the form of diverse fragments of varying shapes and sizes, covered with foreign substances such as soil. In addition, some of the wall fragments exhibited burn marks. White pigment wash was observed on most of the fragments, while some pieces showed traces of coloring in addition to the white pigment wash. Though it was difficult to ascertain the exact nature or appearance of the images solely from these fragments, a visual inspection 
Table 2. Microscope images for sample surface

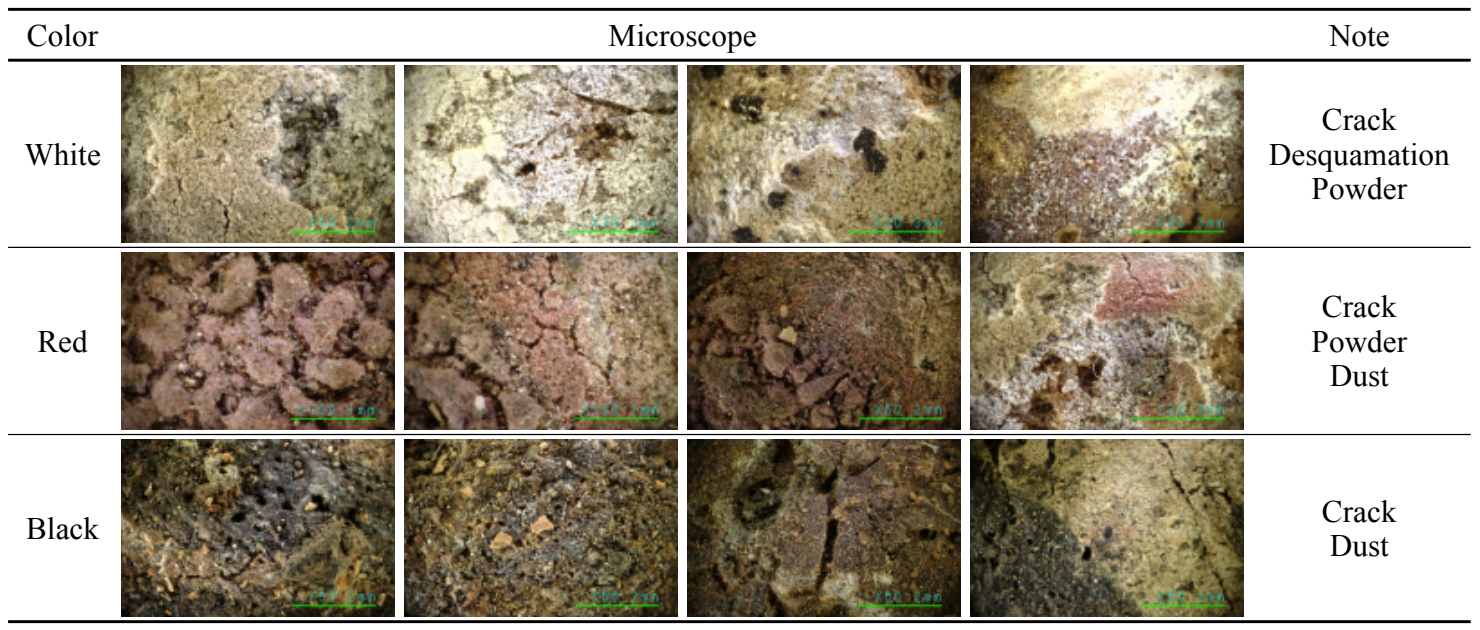

Table 3. Chrominance list $\left(\mathrm{L}^{*} \mathrm{a}^{*} \mathrm{~b}^{*}\right)$ for sample surface

\begin{tabular}{ccccc}
\hline Division & Color & $\mathrm{L}^{*}$ & $\mathrm{a}^{*}$ & $\mathrm{~b}^{*}$ \\
\hline \multirow{3}{*}{ JS1 } & White & 70.36 & 5.87 & 18.71 \\
\cline { 2 - 5 } & Red & 56.87 & 9.11 & 18.32 \\
\cline { 2 - 5 } & Black & 48.35 & 4.85 & 12.94 \\
\cline { 2 - 5 } & White & 65.57 & 4.55 & 12.35 \\
\cline { 2 - 5 } JS2 & Red & 42.56 & 7.53 & 13.55 \\
& Black & 45.49 & 4.58 & 12.91 \\
\hline \multirow{2}{*}{ JS3 } & White & 64.59 & 4.17 & 7.57 \\
& Red & 38.53 & 5.58 & 3.43 \\
\hline
\end{tabular}

revealed that main colors of the images were red and black. On the basis of the colors identified at the time of the visual inspection, the surfaces with red, black and white colored layers were subjected to an examination by portable microscope(Table 2).

The results of this examination showed that surface cracking and peeling were progressing continuously, along with pulverization of the pigments. In addition, the presence of organic substances such as plant roots was observed. As regards JS1, differences in lightness were additionally measured as its white pigment was in relatively better condition. In terms of the lightness of the white pigment, JS1 was lightest, whereas JS2, JS3 were relatively darker. The color difference values for the red and black pigments were similar. The value for black was relatively darker which means that the $a^{*}, b^{*}$ value was closer to a negative value(-), and the black pigment of JS3 was confirmed to be the closest to black. For the red pigment, JS1 was the lightest while JS3 was the darkest(Table 3, Figure 2).

\subsection{Component analysis of pigment}

To analyze the pigment of the main wall, the microstructure of nine fragments( 3 white, 3 black, and 3 red) were observed using an optical microscope and a scanning electron microscope. After Cross-sectional research through microscope, it is colored using pigments on the wall that is made through mixing the organic matter like straws and fibers and clay mineral. Clay mineral used for making the face of wall and the size of pigments' particle is not mild 
but the particle of clay mineral is more close to the layer of coloring, higher the ratio of fine particles is. So, the layer between coloring and clay mineral is obvious. The results of this examination showed that all nine samples were composed of mud-plastered wall body and thin layers of color. The mud-plastered wall body was made up of red brown soil, distributed with grains of many different sizes. For the white sample group of JSW, the color was dark grey, which is less bright than white. In the red sample group, JSR1 and JSR2 were red overall, but partially mixed with white, and though the white color was distributed at a deeper position, the position of color layers was not clearly distinguished. For the black sample group of JSB, JSB2 and
JSB3(but not JSB1), it was confirmed that there was no boundary between the red and black colors. In the case of JSB1, only black pigment was confirmed(Table 6).

The white sample group of JSW was analyzed using an energy dispersive X-ray spectrometer(Table 4), the results of which showed that all the samples contained $\mathrm{Na}, \mathrm{Al}, \mathrm{Si}$, $\mathrm{K}$ and $\mathrm{Fe}$, with $\mathrm{Mg}$ partially existent. A very small amount of $\mathrm{Mg}$ was detected, which indicates that it was part of the impurities contained in soil. The main contents of all three samples were $\operatorname{Al}(17 \sim 23 \%)$ and $\operatorname{Si}(20 \sim 24 \%)$, so they are considered to be the main components(Table 7, Figure 3). The results of X-ray diffractometry showed that both quartz $\left(\mathrm{SiO}_{2}\right)$ and alkali feldspar were present in all the samples.

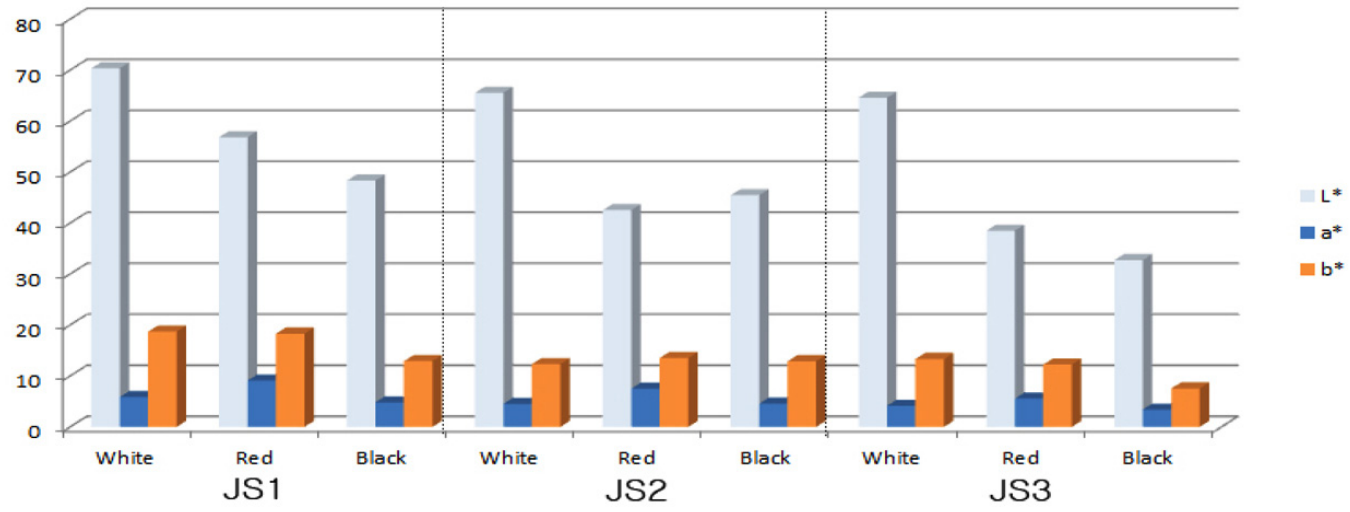

Figure 2. Chrominance graph for pigment of sample surface.

Table 4. Optical microscope image, SEM image list for pigment of sample surface(JSW)

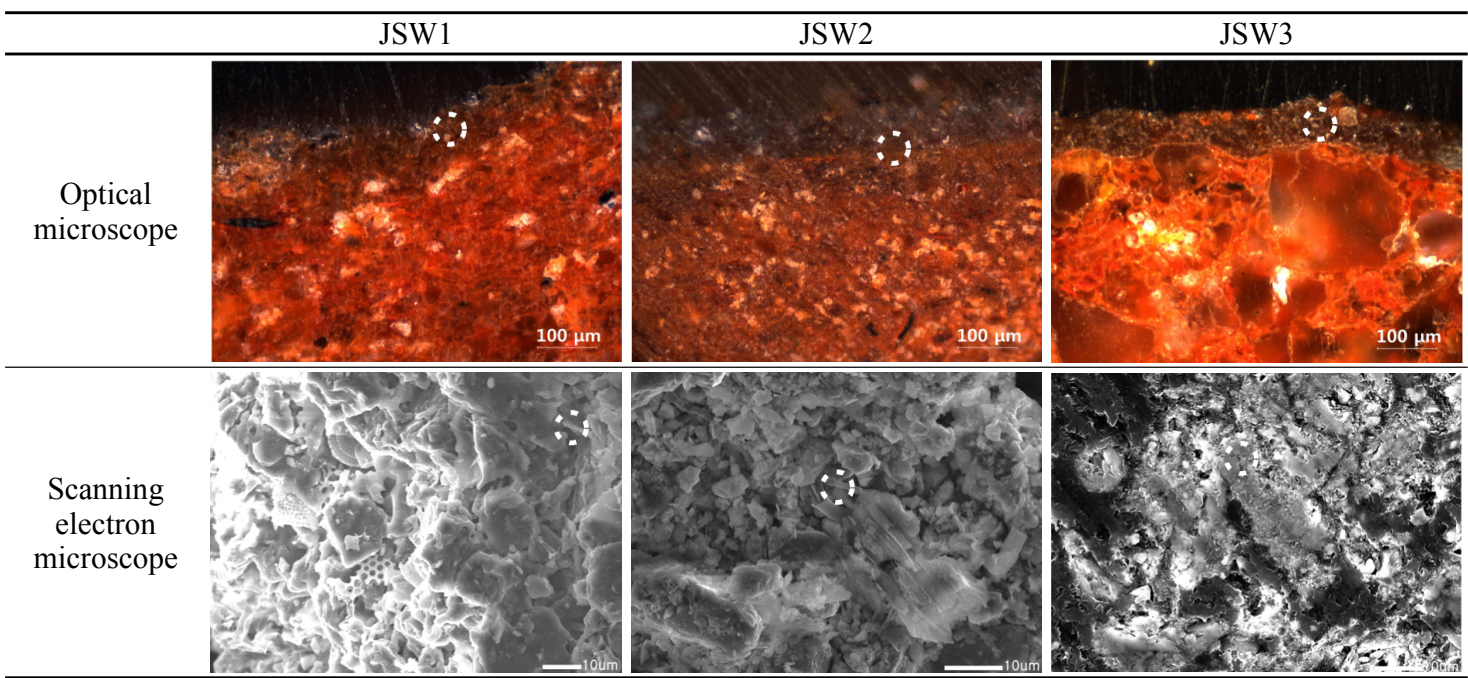


On the other hand, samples JSW1 and JSW2 were confirmed to contain hematite $\left(\mathrm{Fe}_{2} \mathrm{O}_{3}\right)$ and plagioclase $\left(\mathrm{NaAlSi}_{3} \mathrm{O}_{8}\right)$, while JSW2 and JSW3 contained mullite $\left(3 \mathrm{Al}_{2} \mathrm{O}_{3} \cdot 2 \mathrm{SiO}_{2}\right)$ (Figure 4).

The results of the analysis using an energy dispersive X-ray spectrometer(Table 5) of the red sample group of JSR showed that $\mathrm{Al}, \mathrm{Si}$ and $\mathrm{Fe}$ were present in all of the samples, and that $\mathrm{Na}, \mathrm{Mg}, \mathrm{Ca}$ and $\mathrm{Ti}$ were present in small quantities. Among these, the $\mathrm{Al}, \mathrm{Si}$ and $\mathrm{Fe}$ contents were high, and all three samples had a high Fe content. For JSR1 and JSR2, the Fe content was 9 11\%, whereas JSR3 contained $61.62 \%$, which suggests that $\mathrm{Fe}$ is its main component(Table 7, Figure 3).

As a result of X-ray diffractometry, all of the samples were confirmed to contain quartz(SiO2), hematite and plagioclase $\left(\mathrm{NaAlSi}_{3} \mathrm{O}_{8}\right)$, while samples JSR1 and JSR2 also contained mullite $\left(3 \mathrm{Al}_{2} \mathrm{O}_{3} \cdot 2 \mathrm{SiO}_{2}\right)($ Figure 5).

The results of the analysis, using an energy dispersive X-ray spectrometer(Table 6), of black sample group of JB showed that all of the samples contained $\mathrm{Al}, \mathrm{Si}, \mathrm{K}$ and $\mathrm{Fe}$,

Table 5. Optical microscope image, SEM image list for pigment of sample surface(JSR)

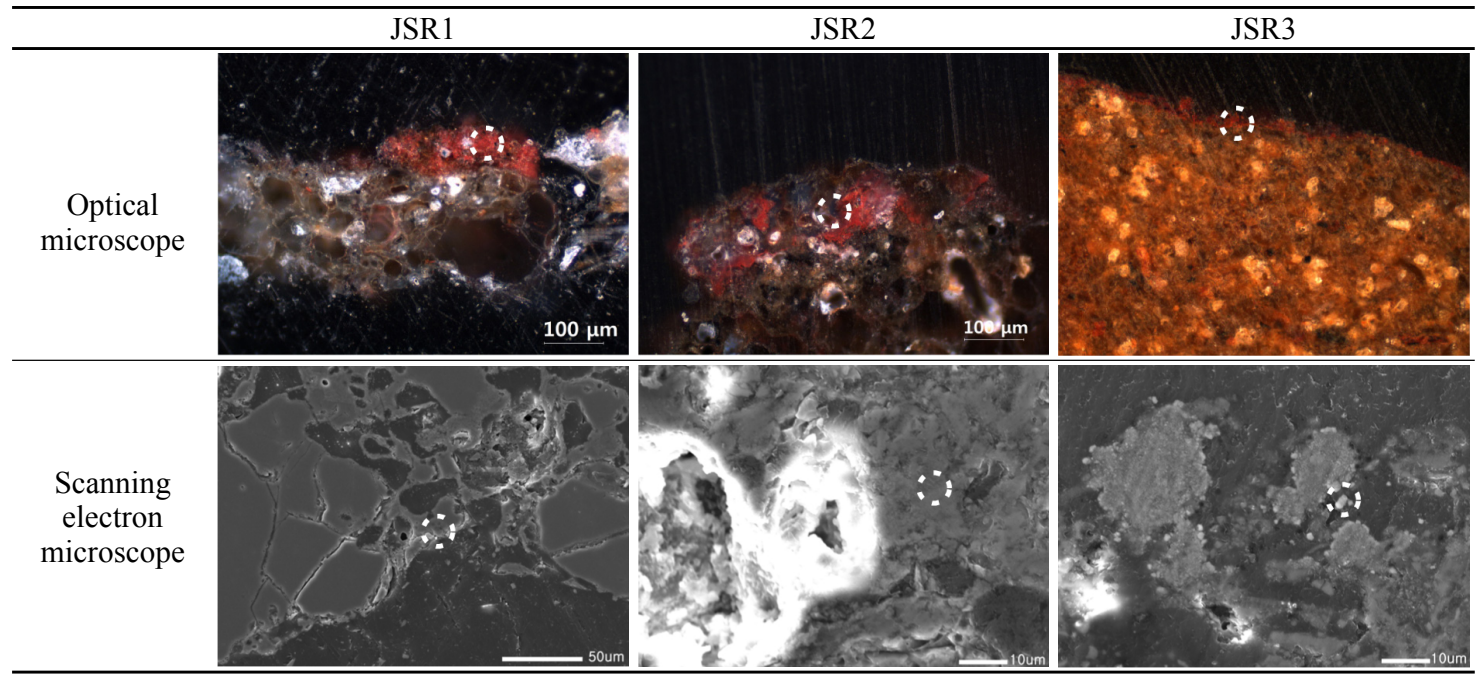

Table 6. Optical microscope image, SEM image list for pigment of sample surface(JSB)

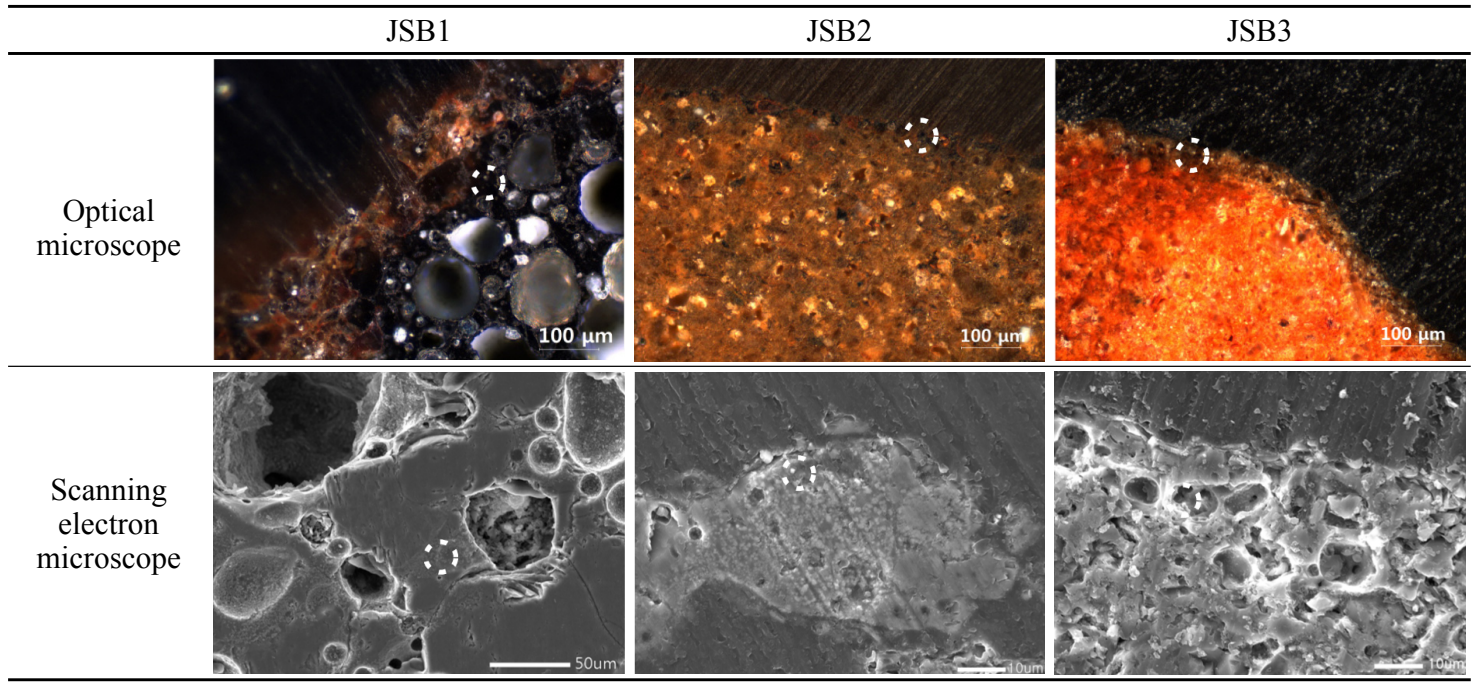


Table 7. EDS analysis results(all result in weight, \%) for pigment of sample surface

\begin{tabular}{|c|c|c|c|c|c|c|c|c|c|c|c|c|c|}
\hline Color & Number & $\mathrm{O}$ & $\mathrm{Na}$ & $\mathrm{Mg}$ & $\mathrm{Al}$ & $\mathrm{Si}$ & $\mathrm{P}$ & $\mathrm{K}$ & $\mathrm{Ca}$ & $\mathrm{Ti}$ & $\mathrm{Mn}$ & $\mathrm{Fe}$ & Total \\
\hline \multirow{3}{*}{ White } & JSW1 & 52.77 & 0.70 & 1.17 & 17.62 & 20.22 & - & 1.84 & 0.23 & 0.21 & - & 5.24 & 100 \\
\hline & JSW2 & 50.68 & 0.38 & - & 22.73 & 23.36 & - & 2.25 & - & - & - & 0.60 & 100 \\
\hline & JSW3 & 48.50 & 0.36 & 0.38 & 21.20 & 22.62 & 0.92 & 2.66 & 0.53 & - & 0.20 & 2.63 & 100 \\
\hline \multirow{3}{*}{ Red } & JSR1 & 49.26 & 0.57 & 2.26 & 17.94 & 17.69 & - & 2.07 & - & 0.75 & - & 9.45 & 100 \\
\hline & JSR2 & 48.20 & - & 13.10 & 0.66 & 26.88 & - & 0.51 & - & - & - & 10.65 & 100 \\
\hline & JSR3 & 34.97 & - & - & 2.43 & 0.99 & - & - & - & - & - & 61.62 & 100 \\
\hline \multirow{3}{*}{ Black } & JSB1 & 46.37 & - & 1.42 & 13.02 & 19.18 & - & 1.68 & - & 0.78 & 1.08 & 16.48 & 100 \\
\hline & JSB2 & 25.20 & - & - & 12.14 & 12.78 & - & 1.36 & - & - & - & 48.53 & 100 \\
\hline & JSB3 & 29.67 & - & - & 11.88 & 30.91 & - & 7.90 & 0.79 & 1.10 & 6.83 & 10.93 & 100 \\
\hline
\end{tabular}

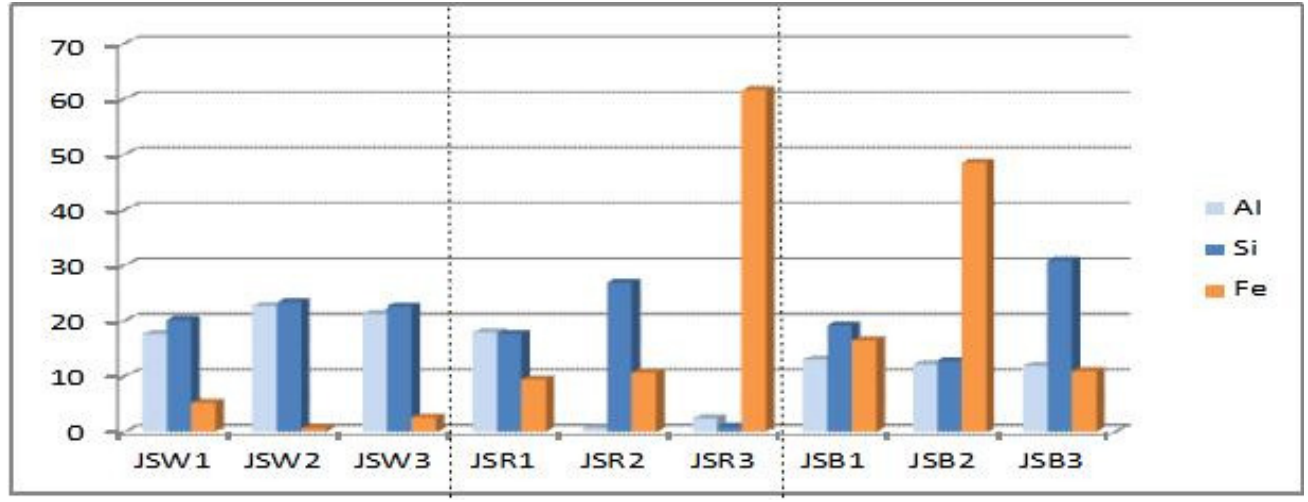

Figure 3. EDS analysis results graph for pigment of sample surface.
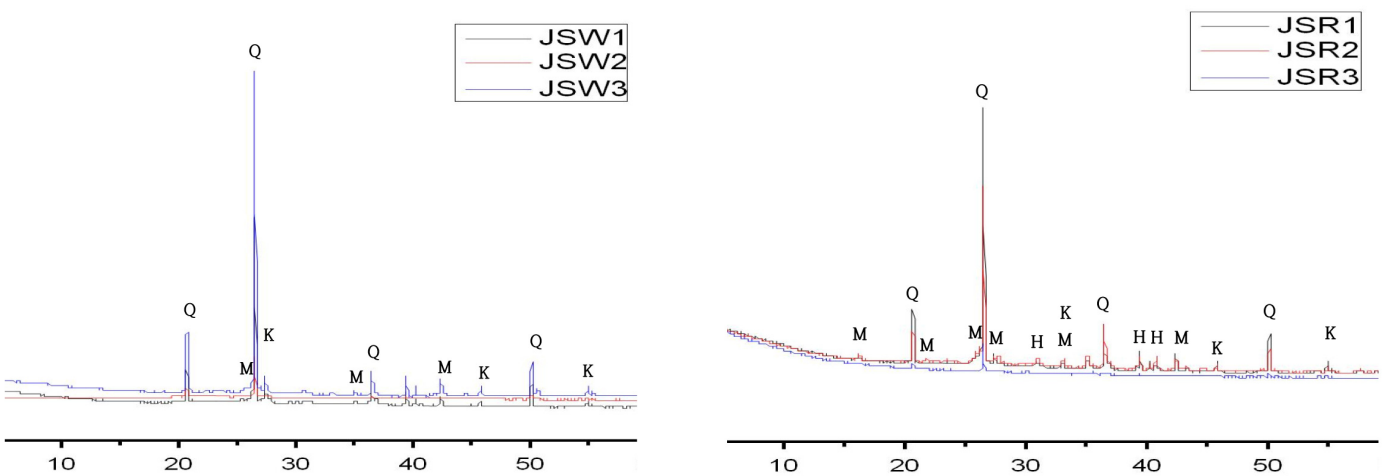

Figure 4. XRD analysis results graph for pigment of sample Figure 5. XRD analysis results graph for pigment of sample surface (Q: quartz. K: alkali feldspar, M: mullite). surface (Q: quartz. K: alkali feldspar, M: mullite, H: hematite, $\mathrm{Mg}$ : magnetite, $\mathrm{P}$ : plagioclase).

i.e. $11 \sim 14 \%, 12 \sim 31 \%$ and $10 \sim 49 \%$, respectively, suggesting that these were the main components. In addition, some samples were found to contain Ti and Mn. The very small amounts of these elements found in some samples are believed to be part of soil impurities(Table 7, Figure 3). X-ray diffractometry showed that the samples contained quartz $\left(\mathrm{SiO}_{2}\right)$, magnetite, plagioclase $\left(\mathrm{NaAlSi}_{3} \mathrm{O}_{8}\right)$ and alkali feldspar(Figure 6). 


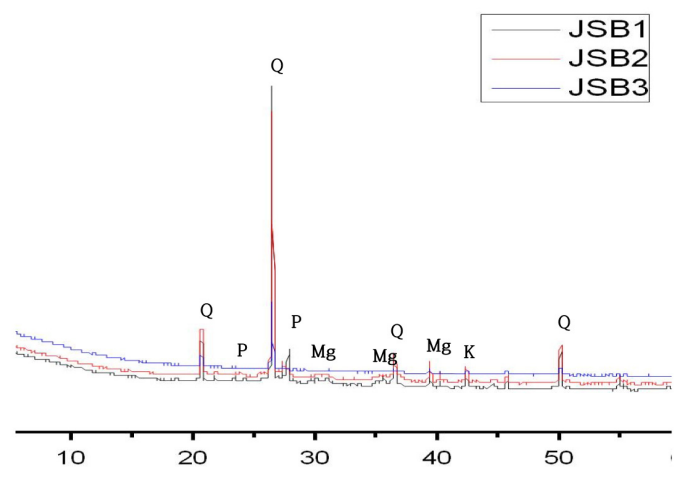

Figure 6. XRD analysis results graph for pigment of sample surface (Q: quartz. K: alkali feldspar, M: mullite, $\mathrm{Mg}$ : magnetite, P: plagioclase).

\section{CONCLUSION}

The results of the analysis of the components of the pigments used in the wall fragments excavated from the dumpsite of the original Jeseoksa Temple are as follows:

1. Fragments of wall painting excavated at the dump site of Jeseoksa Temple site are made by mixing clay mineral and organic matter using main points of woods, etc. and layer of coloring is created by the pigments

2. For the wall features excavated from the site, the thin layer of coloring is assumed to have been created over a wall composed of clay minerals. The color layer is divided into white, red and black. It is assumed that kaolin was added in the case of JSW, the white sample group.

3 . The results of the analysis of the white pigment layer, which is assumed to be pigment wash, showed that quartz $\left(\mathrm{SiO}_{2}\right)$ and alkali feldspar were the main components. In addition, in JSW2 and JSW3, the use of mullite $\left(3 \mathrm{Al}_{2} \mathrm{O}_{3} \cdot 2 \mathrm{SiO}_{2}\right)$ as a white pigment was confirmed, and it is thought that the mullite was produced due to external environmental factors and the effects of plagioclase and feldspar(kim et al., 2013), for which further study is required.

4. The analysis of the layer composed of red and black confirmed that they are iron oxides. The JSR sample group, which is a relatively bright red, was found to contained hematite $\left(\mathrm{Fe}_{2} \mathrm{O}_{3}\right)$, whereas the JSB sample group, which looks black, was found to contain magnetite $\left(\mathrm{Fe}_{3} \mathrm{O}_{4}\right)$. The examination by microscope of the surface of the JSB sample group showed that bright red and dark black pigments coexisted, from which it was surmised that the hematite was reduced due to external environmental factors such as conflagration.

5. Mullite $\left(3 \mathrm{Al}_{2} \mathrm{O}_{3} \cdot 2 \mathrm{SiO}_{2}\right)$, hematite $\left(\mathrm{Fe}_{2} \mathrm{O}_{3}\right)$, magnetite $\left(\mathrm{Fe}_{3} \mathrm{O}_{4}\right)$ is identified as main ingredients, influenced by heat among external environment's factors. Fire at the Jeseoksa Temple site is recorded at Gwanseeum eunheomgi(觀世音應驗記) and possibility about the heat's infleunce by fire is confirmed. But, another factor except for fire on the record is possible to exist, so additional study for investigating the factors is need to be studied.

6. It is expected that this analytical research will be used as basic data in studies of the coloring pigments used in temple wall paintings dating from the Sabi era of the Baekjae kingdom in the Iksan region. Also through this article, we were able to confirm the possibility of a fire or other effects. Thus, based on this article, we plan to further investigate the possibility of a fire by record or other relics.

\section{ACKNOWLEDGEMENT}

This research was carried out with the support of the Baekje Iksan capital city District Operating System Research Project(NRICH-1805-A20F-1), which is a project of the National Institute for Cultural Properties.

\section{REFERENCES}

Buyeo Research Institute of Cultural Heritage, 2011, Research report I. (in Korean)

Buyeo Research Institute of Cultural Heritage, 2013, Research report II. (in Korean)

Kim, S.J., Heo, J.S., Kim, J.H., Kim, D.H. and Han, M.S., 2013, Analysis of physicochemical properties and firing temperature for the clay bricks excavated from, the maritime province of Severia. Korean Journal of Cultural Heritage Studies, 46(2), 206-219. (in Korean)

Yang, E.K., 2014, Mirokusaji excavated mural craft production technique. Prehistoric and ancient, 41, 35-69. (in Korean) 